\title{
Standardised English Language Proficiency Testing for Seafarers
}

\author{
Bernd Mönnigmann ${ }^{a}$, Adelija Čulić-Viskota ${ }^{\text {b }}$
}

This paper aims at pointing out the necessity of raising the levels of both communicative competence and Maritime English knowledge of seafarers, as well as of introducing a common language testing system into maritime education and training. It provides insight into the process of implementation of improvements in a different, but related practice of Aviation English and the relative regulations. Also, the paper presents the accounts of one aircraft accident, and two ship accidents due to the participants' misunderstanding, or deficiency in English. This is followed by the results of an investigation into the reports published by the Marine Accident Investigation Branch (MAIB) about the sea accidents due to inadequate English language competence, or inadequate professional communication. Although there are commonly more than one cause which combine in each accident, these are usually fuelled by inadequate language competence. It is of utmost importance, especially in emergencies, that all the participants in the maritime venture are adequately competent in Maritime English to handle the emergencies to the benefit of all the persons involved. Therefore, the compulsory introduction of a uniform global language certification is suggested.

\section{KEY WORDS}

$\sim$ Maritime English

$\sim$ Aviation English

$\sim$ Language certification

$\sim$ Competence

$\sim$ Emergency a. Flensburg University of Applied Sciences, Flensburg, Germany

e-mail: moema@posteo.de

b. University of Split, Faculty of Maritime Studies, Split, Croatia

e-mail: adelija@pfst.hr

doi: $10.7225 /$ toms.v06.n02.007

This work is licensed under (cc) BY

\section{INTRODUCTION}

The problem of inadequate English language skills among ships' crews is not unknown. In 2016, 85 total losses of ships of $100 \mathrm{GT}$ and above occurred worldwide resulting in 2,611 deaths. ${ }^{1}$ In the subsequent reports and discussion about the actual causes of accidents, technical failure or human error is often cited. In all of the cases, there is clearly an instantaneous overload of the ship's structure, its technical facilities, or the people entrusted with conducting the ship shortly before the accident. A current report by the ship classification society Det Norske Veritas / Germanischer Lloyd (DNV / GL) assesses the share of human error at approximately $85 \%$. $^{2}$ The proportion of the technical failure is thus approximately $15 \%$.

The avoidance of a technical failure is a task for engineers, whose results are continually reviewed and improved. Overall equipment requirements are leading to progressive mechanisation, automation, and digitalization of ships'operation, a development which includes an increased surveillance of the crews. One such example was the introduction of Voyage Data Recorder on civilian ships starting from 1 July, 2002. ${ }^{3}$ These are comparable to Black Box flight recorders, which had existed for several decades in civil aviation before the date mentioned.

In the following parts 1 and 2.1, there is reference to Aviation English, as the participants in the air traffic have already realised the importance of common occupational and working language in the avoidance of accidents, and have implemented the necessary changes.

In order to emphasise the importance of Maritime English as occupational and working language in shipping, an analysis of MAIB reports of accidents at least partly due to language

1. Source: Allianz Safety and Shipping Review 2017, available at: http://www. marifuture.org/Publications/Papers/COMMUNICATION_AND_PRACTICAL_ TRAINING_APPLIED_IN_NAUTICAL_STUDIES.pdf

2. Maritime Impact magazine (2014)

3. International Convention for the Safety of Life at Sea, Issue 2017, Chapter V, Rule 20, Number 1.1 
incompetency in either General or Maritime English, or both is presented in the part 3 below.

Finally, the need for introduction of a uniform Maritime English testing system is emphasized as means of achieving more balanced Maritime English competence among crewmembers and, thus, raising the level of safety at sea.

\section{THE RELEVANT GUIDELINES OF AVIATION ENGLISH}

At present, to man seafaring vessels the crewmembers are still not required to present any uniform language certificate. By comparison, the currently existing language certificates in the field of civil aviation were introduced in a globally uniform format by the International Civil Aviation Organisation (ICAO) with the Manual on the Implementation of ICAO Language Proficiency Requirements, the ICAO Doc 9835, during the 2004-2008 period. This procedure requires the acquisition of a language certificate confirming at least the English language level 4 ('Operational') ${ }^{4}$ proficiency for any air-borne or ground personnel entrusted with safety-relevant tasks.

Table 1.

Language Proficiency Levels.

\section{CEFR Common European Framework of Reference for Languages}

C2 Proficiency

C1 Advanced

B2 Upper Intermediate

B1 Intermediate

A2 Elementary

A1 Beginner

Another example is the required language performance testing for certain careers in the Bundeswehr (German Armed Forces). Here, the responsibility lies with the Federal Office of Languages (Bundessprachenamt) in Cologne/Hürth as well as its approximately 100 service centres, e.g. at the Naval Academy Mürwik at Flensburg. The Federal Office of Languages offers total training in over 40 languages.

4. The ICAO language testing system is divided into 6 levels. Currently, each pilot that is flying internationally must have a minimum level 4 of ICAO English. The exam must be done in an authorized organization. As regards to the validity of ICAO language proficiency certificates, the revalidation which one must undertake is determined by the level achieved: Level 4 - every 3 years, Level 5 - every 6 years, Level 6 - unlimited

\section{COMMUNICATION AS A SOURCE OF ERROR}

There are various causes of human error in shipping. Due to the lack of available statistics, reference is made here to publicly accessible accident investigation reports. The high number of ship's Deck Officers involved in accidents corresponds to the typically higher risk related to the job profile of navigating seagoing ships. The study The Human Element - a Guide to Human Behaviour in the Shipping Industry, published in 2010 with the support of the UK Maritime and Coastguard Agency, asserts that communication failures are common and have serious consequences in safety-critical industries such as seafaring. According to Gregory, D., Shanahan, P. (2010: 83), these failures account for over $25 \%$ of the accidents.

The objectively problematic language situation in the civilian seafaring is typically addressed with various strategies during normal ship operation. The use of hand signals, repeated orders or requests for clarification, along with intuitive action replaces "clear communication" as defined by the international STCW Convention ${ }^{5}$ in many cases. This can work when it comes to routine procedures, but immediately after the onset of a marine accident, more complex and at the same time also completely specific communication competences are required. Not only may these differ technically from the usual communication content, but the number of potential communication participants is also multiplied. After experiencing a grave accident, the crew has to coordinate and communicate about not only the damage control on board, but also with other craft in the vicinity, as well as with land-based services. "Clear communication" as required by the STCW Convention should now be used. If the individual language users are overdemanded, the entire accident response is at risk.

\subsection{Aviation and Marine Accidents Due to Language Difficulties}

The worst accident in the history of aviation happened on 27 March, 1977 at the Airport Los Rodeos on the island of Tenerife. While the just-landed Pan Am Boing 747 was rolling towards the terminal, another KLM Boing 747 was waiting for its take-off clearance. The communication between the Captain and the Flight Engineer in the cockpit of the waiting KLM aircraft was recorded by the voice recorder. At 17:06:32 the Flight Engineer asked: "Is he not clear, then?" Two seconds later the Captain replied: "What do you say?" At 17:06:34 the Flight Engineer repeated: "Is he not clear, that Pan American?" A second after that, the Captain said in an emphatic tone: "Oh, yes!" The take-off, the moment a plane loses contact with the earth, was recorded at 17:06:44. Six seconds later, the two aircrafts collided. 583 people

5. International Maritime Organization (2011), International Convention on Standards of Training, Certification and Watchkeeping for Seafarers, Table A-II/1 
did not survive this collision, only 61 escaped. The official accident investigation concluded it was the Pilot's error. Apparently, the communication with the tower did not make clear whether the arriving Pan Am aircraft had already cleared the runway. As a consequence of this accident, new communication procedures were adopted: "Ready for take-off" was changed into: "Ready for departure", to avoid confusion with the phrase: "Cleared for takeoff'.

The second example involves the grounding of the $M / V$ S. Gabriel on the southern coast of the Acores on 21 November, 2009. The M/V S. Gabriel is a multi-purpose vessel with about 100-metres' length and the loading capacity of 5,560 tons, sailing under the flag of Germany. Running aground on the rocky coast of the Acores happened in the early morning hours, at about 05:00 local time. The $2^{\text {nd }}$ Deck Officer obviously fell asleep, and therefore failed to alter course in time. The $2^{\text {nd }}$ Deck Officer was of Bulgarian nationality, while the Captain was of German nationality. The working language on board was, as usually, English. Following the stranding, the Captain awoke. The communication at the time the Captain entered the navigating bridge (wheelhouse) was recorded by the ship's Voyage Data Recorder. First, the Captain exclaimed: "Oh, my God! End of my... What's going on, Second?" The $2^{\text {nd }}$ Officer replied: "Uh, Captain; I try to...... ". Then, the Captain asked: "Where we are? Were you sleeping?"This was answered by the $2^{\text {nd }}$ officer saying: "No. But...... I just...... ". After a short while, the Captain ordered: "Give alarm! Wir sind völlig am Arsch! Wir hängen auf Grund! Wir saufen ab! Du bist gegen die Felsen gefahren!" (From German original into English: "We are totally screwed! We are aground! We are drowning! You have been sailing against the rocks!") Two things can be noticed here: the Captain first approached the $2^{\text {nd }}$ Deck Officer in the working language. As the Captain realized that he was receiving no usable feedback to his questions, he fell back into his own mother tongue. Mitigating circumstances could be that the $2^{\text {nd }}$ Deck Officer was in a state of shock. On the other hand, members of the ship management must be in the position to communicate clearly under all circumstances.

The third example was extracted from the official accident report about a very serious accident involving the cruise ship Sapphire Princess on 7 August, 2014 in the East China Sea. Sapphire Princess with the length of 290 metres sailed under the flag of the United Kingdom. On the day of the accident, Sapphire Princess carried 4,095 persons, of which 2,998 were passengers, the other 1,097 persons on board belonged to the crew. The majority of the passengers were Chinese, while the crew was multi-national. A number of Chinese-speaking Customer Service Agents (CSA), and other crew members of various nationalities had been employed. Passenger information documents and some ship's signage were translated into Chinese. At approximately 12:45 hours local time, a passenger was noticed floating face-down in the Neptune swimming pool. In the absence of a dedicated pool attendant, the initial alert was raised by some passengers. At 12:47 hours, a member of the catering staff dialled the internal ship's alert number '911' using the onboard emergency services telephone. The CSA receiving the call could not understand him and passed the telephone to another CSA who, in turn, transferred the call to the duty nurse. The nurse received the call at 12:49 hours, at which point the caller reported that a female passenger had been pulled out of the pool and was unconscious. Following the receipt of the emergency call, the duty nurse retrieved the First Response Bag, ran to the medical centre and explained the nature of the emergency to the senior doctor and senior nurse. They all then proceeded to Neptune Pool. On arrival, the medical team noticed some five passengers and a similar number of crew members in the vicinity of the victim, but they also noticed that CPR (cardio-pulmonary resuscitation) was not being carried out. The doctor and the duty nurse began CPR, while the senior nurse fetched the ship's Automated External Defibrillator; the pads were applied to the victim's chest, but the device indicated 'No Shock Advised'. CPR was then resumed and supplementary oxygen administered. The victim was transferred to a gurney, where resuscitation attempts continued and adrenaline was administered intravenously. Despite the rescue and resuscitation attempts, the victim was pronounced deceased at 12:55 hours.

However, there was a short delay in the emergency team response due to the language difficulties among the crewmembers. Once the alarm was raised, the response to the incident by the ship's emergency medical team was rapid and professional. It cannot be determined how long Ms. Bayinhua had been lying face-down in the water before her predicament was noticed. The working language on board was English. However, the initial emergency call from a Serbian catering assistant working in the Deck 14 food area to an Asian CSA in the Purser's office was not understood due to language difficulties. Fortunately, another CSA was able to understand the caller, otherwise the medical team's response might have been further delayed. These delays might have compromised the effectiveness of the emergency response.

\section{INVESTIGATION INTO MAIB ACCIDENT REPORTS}

The Marine Accident Investigation Branch (MAIB), established in 1989 following the Herald of Free Enterprise disaster, is a branch of the United Kingdom Department for Transport which can investigate any accident occurring in the UK waters, regardless of the nationality of the vessel(s) involved, and accidents involving UK-registered ships worldwide. The aim is to present publicly safety lessons which may be learned as a result of the investigation.

The investigation into MAIB reports was based on three key words: 'language','communication', and 'English'. 
On entering the key word 'language' into the webpage search engine, 4 reports were returned among which there was the already discussed accident involving the cruise ship Sapphire Princess. The key word 'English' also returned 4 reports including St.Georgij and Ocean Harvest II accidents, while the key word 'communication' returned 32 reports. Among the latter, 13 referred exactly to language communication, while in the remaining 19 reports the word 'communication' was found as referring to either communication equipment on board ships involved in the accidents, or crewmembers' interpersonal communication in the sense of a process based on other factors than language.

Table 2 below shows the results of the investigation, and presents the remarks or recommendations of the Chief Inspector in each of the cases. This points out different aspects of professional communication either praised, or blamed for accidents.

Table 2.

Results of MAIB reports investigation.

No. Accident:

1. Fire in engine room on Panamanian-flagged, 1984-built bulk carrier St Georgij with 1 person injured and loss of 1 life (19 December, 2005)

2. Fire and sinking of UKflagged, 1972-built fishing vessel Ocean Harvest II (3 July, 2006)

3. Drowning in swimming pool on the UK-flagged, 2004-built passenger cruise ship Sapphire Princess with loss of 1 life (6 August, 2014)

4. Collision between fishing vessels Immanuel $\boldsymbol{V}$ and UKflagged 1972-built Scath Ros resulting in Scath Ros sinking (10 July, 2005)

5. Parting of messenger line from tanker Queen Zenobia (18 June, 2005)

6. Collision between pair trawlers UK-flagged, 1999-built Fertile II and UKflagged, 1999-built Aquarius resulting in Fertile II sinking (28 May, 2005)
Chief Inspector's remarks / reccommendations:

improvements in key personnel's ability to read English instruction books or have manuals translated into the working language of the crew

... courses should be provided that are suitable for those that do not have English as their first language.
Language skills referred to:

- Requirement for English as working language

- Reading skill

improvement

All skills required there was a short delay in the emergency team response due - Speaking skill to language difficulties between crew members
To ensure all crewmembers can communicate effectively in a - Speaking skill (SMCPs common language, especially during emergency situations. in emergencies)

\section{Ensure ship's crews establish contact and maintain basic communication between themselves and tug crews when working together.}

The Chief Inspector wrote to the skipper of Aquarius regarding the standard of lookout, communications and maintenance procedures and to the skipper of Fertile // regarding the standard of lookout, communications, use of life saving equipment and the use of VHF in the initiation of a Mayday call.
- Speaking skill (SMCPs for Tug Assistance ${ }^{6}$ )

- Speaking skill (SMCPs for VHF communication in emergencies)

6. More about SMCPs for Pilotage and Tug Assistance, and the requirement to use English as the only working language in these activities instead of the use of local languages for communication between the bridge team and the tug/s, in CulicViskota, A. (2014), (2015) 
7. Collision between sailing yacht Ibis and Liberianflagged 2000-built container vessel OOCL Malaysia resulting in Ibis sinking (06 February, 2005)

8. Contact made by Gibraltarflagged German-owned oil product/chemical tanker Apollo with quayside (25 July, 2013)

9. Grounding of Bahamasflagged, German-owned, 1997-built passenger cruise ship Hamburg (11 May, 2015)

10. Collision between UKflagged 2007-built container vessel CMA CGM Florida and Panamanian-flagged, 2004-built bulk carrier Chou Shan (19 March, 2013)
11. Grounding and capsize of French berthed trawler Saint Christophe 1 resulting in loss of the vessel (10 March, 2016)
To Associated British ports: - regarding methods of improving communications between the patrol launch and small vessels.

It is of course fundamental to establish and maintain good, clear and concise communications.
- Speaking skill (VHF communication)
- Speaking skill (VHF communication)
Although English was the working language on board Hamburg, several conversations were in other languages. Had the SMS been followed, the announcement would have first been made in English, the working language on board, followed by German.

The only announcement following the grounding was made in German and not in the working language on board which was English.

The working language on CMA CGM Florida was English. The working language on Chou Shan was Mandarin.

The Filipino OOW asked the Chinese $2 / 0$ to do this because he believed there would be a better chance of a positive outcome from the VHF radio call if it was made in Mandarin, which he assessed to be the likely first language of the fishing vessel crews.

When he was asked by the Filipino OOW to call the fishing vessels on the VHF radio, he readily accepted the task believing his ability to communicate externally, in the local language, to be helpful in the circumstances. Use of the VHF radio for collision avoidance was common practice in his experience. ... they were both hampered in their attempts to communicate by having to converse in a second language. A significant contributing factor to this misunderstanding was that the communication was conducted in a language which the Filipino OOW was unable to understand.

Even where positive identification has been achieved there is still the possibility of a misunderstanding due to language difficulties however fluent the parties concerned might be in the language being used. An imprecise or ambiguously expressed message could have serious consequences.

Although one of the river officers attempted to explain the limitations of the berth using hand gestures to the skipper of Saint Christophe 1, the skipper did not understand the communication.

The investigation also identified that the Harbour Authority was fully aware that Saint Christophe 1 would ground on the falling tide but, due to language difficulties, its staff were unable to make the fishing vessels' skippers aware of this.
- Requirement for English as working language - Speaking skill (VHF communication - SMCPs in emergencies)

- Requirement for English as working language - VHF communication (SMCPs for VHF communication) - Requirement for clear and unambiguous language

- Requirement for English as working language - Speaking skill (use of SMCPs in navigational warnings) 
12. Person overboard from cable laying vessel Tycom Reliance with loss of 1 life (25 June, 2006)

13. Parting of rope during hauling operation on UKflagged, 1982-built twin-rig trawler Hendrika Jacoba with loss of 1 life (20 April, 2010)

14. Grounding of UK-flagged, 1991-built potter Niamh Aine (22 March, 2009) poor internal communication

Speaking skill

(SMCPs for Internal

Communication)

Consider further risk control measures such as organisation, supervision, effective communications (between bridge and mooring station $\mathbf{s}^{7}$ ) and clearly marked snap-back areas.

- Speaking skill (SMCPs for Internal Communication)
The Deputy Chief Inspector of Marine Accidents has written to the vessel's owner:

- commending the professional manner in which the skipper and crew responded to the accident, particularly with regard to the skipper's calm and clear communications with the coastguard and rescue helicopter during the rescue.

15. Close-quarters situation involving Cyprus-flagged, 1989-built liquefied petroleum gas tanker Monsoon and its contact with mooring dolphin (23 August, 2008)

16. Failure of main engine on UK-flagged, 1997-built product tanker Audacity and subsequent parting of tow rope from Spanish-flagged, 2005-built tug Red Wolf with 1 person injured (19 April, 2007)

17. Contact made by UKflagged, 1982-built tractor tug Svitzer Constance with lock gate (03 September, 2009)

18. Contact made by UKflagged, 1992-built oil product/chemical tanker Stolt Petrel with lock gate (07 April, 2009)

19. Machinery failure and subsequent flooding of UK-flagged, 1973-built long liner Port of Ayr (29 October 2009)
The Deputy Chief Inspector has written to the Pilot, strongly advising him to:

- Keep VTS fully informed of any intended course of action

- Maintain full situational awareness by gaining information on all scheduled ship movements before boarding, and utilising the bridge team to relay relevant communications and traffic information as necessary.

The Chief Inspector of Marine Accidents has written to the: Owner and Managers of Audacity, strongly advising that they: -Emphasise the need for effective communications to be maintained between company vessels and tugs, or other vessels, engaged in towing.
ABP Humber has circulated a Notice to Pilots, to all Pilots and Pilotage Exemption Certificate (PEC) holders, summarising the accident and stating various future measures, including: - Proper concise planning is to be agreed between bridge teams and tugs, together with clear and unambiguous communication, to ensure safe operations.

The Chief Inspector of Marine Accidents has written to the company:

- Ensure that all crew are aware of the risks of parting mooring lines, and the need for good communication between the master and crew at mooring stations.

The examination noted that none of the crew held a professional Certificate of Equivalent Competency (CEC), and there was no English speaker on board.
- Speaking skill praised (SMCPs for VHF communication with Coastguard and rescue helicopter)

\section{Speaking skill}

- Requirement for English as working language for Pilotage (SMCPs for Pilotage and Tug Assistance)

Speaking/listening skill (SMCPs for VHF communication for Tug Assistance)

\section{Speaking/listening}

skill

- Requirement for English as working language during Pilotage and Tug Assistance

- Speaking/listening skill (SMCPs for Mooring)

Speaking/listening skill

- Requirement for English as working language

7. Clarification added by the authors 
As it clearly results from the Table 2 above, in all of the accidents listed either the inability to use the working language Maritime English, the deficiency in the performance of the most important communicative skills - speaking/listening, or both can be observed. Furthermore, the importance of using English as occupational language in shipping has again been emphasized for the Pilotage and Tug Assistance, as well as Mooring, areas which still lack the approval of all the participants in the relative operations to use English exclusively as working language.

\section{MARITIME ENGLISH COURSES AND HETEROGENEOUS PREVIOUS EXPERIENCE}

From the instructor's perspective, the problem lies in offering generally attractive lessons for classes with widely differing degrees of prior knowledge. While the German Armed Forces can arrange more numerous courses, with students at nearly equal language proficiency levels due to a high number of participants, smaller maritime training institutions only have the option of targeted and problem-oriented language promotion in conjunction with well prepared internal differentiation. The idea of an early learning level survey to avoid false evaluations by the teacher seems very reasonable under these conditions.

A 2012 paper titled Communication and Practical Training Applied in Nautical Studies ${ }^{8}$ describes the results of a survey in which 64 instructors of Maritime English from 30 maritime academies and universities worldwide participated. The following estimates refer to the 6-stage Common European Framework of Reference for Languages. The English language proficiency level of the students from these 30 respondent maritime academies and universities worldwide was specified as $5 \%$ at the level "Beginner" and $19 \%$ at the level "Elementary". For the 64 instructors surveyed, "Upper Intermediate" was the minimum recommended level for the command of a ship, and in some cases even the highest level, "Proficiency", was required.

\subsection{Individual Testing Criteria}

The criteria to pass an exam at the maritime training institutions are often decided individually. This burdens the examiners with a choice between compliance with the predefined testing criteria and the (unofficial) goal of a minimal failure rate, a choice complicated by the desire to prevent potential candidates migrating to other maritime training institutions. Uniform language certificates would not only ensure comprehensive adherence to the English Language Minimum Competency levels, but would also provide relief for the examiners.
Appropriate language tests tailored to the specific demands of the merchant navy are already available on the market. For example, the Glasgow-based MARLINS Company, according to its own information leader in the area of E-Learning and Language Assessment, offers high-quality and low-cost online training courses. The ISF Marlins English Test for Seafarers was developed in close cooperation with the International Shipping Federation (ISF) and is already accepted by several flag states and the UK Maritime Coastguard Agency. The ISF Marlins English Test for Seafarers consists of an on-line test in which 85 questions must be answered within 60 minutes. The test questions are divided into various areas of expertise and are explained clearly in multiple languages before the actual test begins. In addition to this online test, there is also a 20-minute Test of Spoken English (TOSE). There are currently 198 Marlins test centres in 41 countries offering language certificates under test conditions. The official recognition (flag state approval) of the ISF Marlins English Language Test for Seafarers already exists in the countries of Great Britain, Ireland, Bulgaria, and Australia.

\subsection{Approved Tests on the Market}

In the meantime, the ISF Marlins English Tests for Seafarers has been chosen by many crewing companies as the in-house solution. The IMO's (International Maritime Organisation) requirement, as outlined in the International Safety Management Code, saying that "the company should ensure that the ship's personnel are able to communicate effectively..." can thus be reasonably satisfied. Then, the Maritime English Instructor Training Course (MEITC), a course developed by Marlins for the IMO, which aims at enhancing the qualifications of the instructors of Maritime English, should not remain unmentioned either. Yet another current advance is the SeaTALK project, funded by the EU Leonardo da Vinci lifelong learning programme. The freely available training materials of the SeaTALK project, which are based on the policies of the communicative approach defined in the IMO Model Course 3.17 for Maritime English, are compiled under the direction of World Maritime University in Malmö (Sweden), in cooperation with nine European maritime training institutions. The training materials are rated according to the skills, refer to the various positions on board the vessels, and are suitable for self-study in addition to being a reference for Maritime English instructors and all other interested parties free of charge. The materials developed in the SeaTALK project form the basis for language competency to be acquired in the individual branches of maritime transport, as well as for the certificates to be acquired in the future. The SeaTALK project refers also to the MarTEL language testing module, developed in the framework of the EU's Leonardo da Vinci programme. 


\subsection{Time Lag in Shipping}

The maritime sector is not known for its rapid implementation of advanced ideas, but the basis for the introduction of uniform language certificates for seafarers is available. Several maritime training institutes, organisations and companies are taking part in their formulation.

This issue has been intensively discussed for many years within IMLA (International Maritime Lecturers' Association). The International Maritime Organisation (IMO) has issued a technical manual along with the Maritime English Model Course 3.17. The Maritime Safety Committee (MSC), the international competency body belonging to the IMO, is currently struggling with international coordination problems. However, the introduction of uniform global language certificates for seafarers is foreseeable. Of course, individual flag states possess the freedom to initiate compulsory introduction of language certificates within their national waters. The introduction of such measures would lead to an improvement in the general level of education in the civilian shipping industry, and as a result many human victims, complicated rescue operations, pollution, and high economic losses could be avoided. Finally, this is all about the closure of a still-existing safety gap.

\section{CONCLUSION}

From the data presented above and the relative discussion, it can be concluded that:

1. The ICAO has long recognised the importance of the introduction of uniform testing of the English language proficiency of the personnel involved in the air traffic. IMO should follow in these footsteps because the Maritime English competence levels of seafarers and others involved in the field of maritime affairs differ significantly.

2. As it follows from the discussion of one air and two maritime accidents above, the knowledge of the specific working language can have the crucial role in the occurrence, or avoidance of an accident. Also, the investigation into MAIB accident reports according to the key words 'language', 'English', and 'communication' has shown that poor communication either causes, or contributes among other causes to the occurrence of an accident.

3. The level of the English language competence of seafarers should be raised and levelled. This can best be achieved by introducing a uniform Maritime English testing system for all seafarers. The achieved knowledge of Maritime English of the present-day seafarers on completing their education differs greatly. The introduction of a common testing system would contribute to effacing the differences by standardising the testing procedures and materials. The knowledge of General English and Maritime English should be tested by adequate tests, but a test of communicative competence, insisting on the listening and speaking skills in particular, is considered just as important and should be conducted as part of the proficiency testing.

\section{REFERENCES}

A New Safety Mindset will Help the Industry Improve its Track Record, (2014), Maritime Impact Magazine, 2014(01), pp. 20 - 26., available at: http://www.dnvglsource.com/assets/documents/src/maritime_impact_issue_01_2014.pdf

Čulić-Viskota, A., (2014), Essential English for Pilotage and Tug Assistance: a Proposal for SMCP Extension, Transactions on Maritime Science, 3 (2), pp. 158-164., https://doi.org/10.7225/toms.v03.n02.007

Čulić-Viskota, A., (2015), SMCP Development for Pilotage and Tug Assistance in the Light of Diffusion of Innovations Theory, Transactions on Maritime Science, 4 (2), pp. 140-150.,

https://doi.org/10.7225/toms.v04.n02.006

Gregory, D., Shanahan, P., (2010), The Human Element, a Guide to Human Behaviour in the Shipping Industry, Norwich: The Stationery Office (TSO), p. 83.

ICAO English Language Proficiency Exams for Aviation Personnel, (2017), available at: http://flight-examiner.com/icao-english/icao-exam, [accessed 24 June 2017.].

International Convention for the Safety of Life at Sea, (2017), London, UK: IMO Publishing.

MAIB web page, (2017), https://www.gov.uk/government/organisations/marineaccident-investigation-branch, [accessed 18 April 2017.].

Mönnigmann, B., (2015), Mehr Sprachliche Kompetenz auf See, Hansa International Maritime Journal, 152(9), pp. 33-35.

Mönnigmann, B., (2017), Marlins-Sprachtests jetzt auch in Flensburg, Hansa International Maritime Journal, 154(1), pp. 47.

Safety and Shipping Review 2017, (2017), report, available at: http://www. agcs.allianz.com/insights/white-papers-and-case-studies/safety-and-shippingreview-2017, [accessed 30 June 2017.].

Ziarati, M., Ziarati, R., Bigland, U. and Acar, U., (2012), Communication and Practical Training Applied in Nautical Studies, Tuzla, Istanbul: Centre for Factories of the Future, Coventry University Technology Park, Coventry, UK and TUDEV Institute of Maritime Studies, available at: http://www.marifuture.org/Publications/Papers/ COMMUNICATION_AND_PRACTICAL_TRAINING_APPLIED_IN_NAUTICAL_STUDIES. pdf, [accessed 27 March 2017.]. 